Article

\title{
An Improved Mathematical Model for Green Lock Scheduling Problem of the Three Gorges Dam
}

\author{
Xu Zhao ${ }^{1}$, Qianjun Lin ${ }^{1}$ and Hao $\mathrm{Yu}^{2, * *(1)}$ \\ 1 College of Economic and Management, China Three Gorges University, Yichang 443002, China; \\ zhaoxu@ctgu.edu.cn (X.Z.); skylin0401@163.com (Q.L.) \\ 2 Department of Industrial Engineering, UiT The Arctic University of Norway, Lodve Langesgate 2, \\ 8514 Narvik, Norway \\ * Correspondence: Hao.Yu@uit.no; Tel.: +47-76966351
}

Received: 4 April 2019; Accepted: 1 May 2019; Published: 8 May 2019

\begin{abstract}
In recent years, the environmental pollutions at the Three Gorges Dam have become an increasingly concerning issue of the Chinese government. One of the most significant environmental problems is the carbon emissions from the lockage operations at the two ship locks of the Three Gorges Dam. Currently, due to the large amount of vessels passing through the dam, there is always a long queue of vessels on both sides and the average waiting time is long. This has further lead to an increased amount of fuel consumption and carbon emissions. Therefore, it is of great importance to develop a decision-support model for a better navigation scheduling and planning of the lockage operations at the Three Gorges Dam. This paper proposed an improved mixed integer non-linear programming model for the green lock scheduling problem at the Three Gorges Dam. The model aims at minimizing the carbon emissions and the waiting time in the lockage process through scheduling the vessels in a fairer and more efficient manner. Moreover, a greedy particle swarm optimization (G-PSO) algorithm is developed to solve the complex optimization problem. The proposed mathematical model and algorithm are validated through a numerical experiment. The result shows that it may lead to a significant reduction on carbon emissions by giving a specified speed to each vessel with a pre-optimized sequence. Meanwhile, the fairness and efficiency of the lockage process may also be improved.
\end{abstract}

Keywords: green scheduling; carbon emissions; green logistics; sustainable development; optimization; mixed integer program

\section{Introduction}

In recent years, with the rapid development of the Yangtze River economic belt, the waterway transportation on the Yangtze River has become increasingly busier. The Three Gorges Dam on the Yangtze River is the world's largest hydropower project, and it has become the world's largest power station since 2012 with 22,500 megawatt (MW) installed capacity [1]. On the one hand, the electricity generated by the hydropower from the Three Gorges Dam provides sufficient power supply to the east of China. However, on the other hand, it also becomes a bottleneck for the waterway transportation due to the capacity limitation of the ship lock, and the inefficient navigation and operations. When passing through the Three Gorges Dam, most medium and large-sized vessels have to use the five-stage ship lock in order to overcome the water-level difference on both sides of the dam, whose operations are time consuming. The drastically increased amount of vessels in passing through the dam has therefore become a significant challenge for the Three Gorges Navigation Administration (TGNA) who is responsible for the navigation scheduling of the vessel sequence and the planning of the lockage 
process. Based on the statistics given by the TGNA, the cargo volume passing through the dam has exceeded 1.01 billion tones in 2018.

Currently, the navigation scheduling and the planning of the lockage process are made in accordance with several predetermined rules and regulations and mostly by experiences, which cannot effectively solve the congestion problem at the Three Gorges Dam. At the peak time, on average, there are more than 200 vessels waiting at the anchorage, and the average time spent in passing through the dam is approximately $30 \mathrm{~h}$. The vessels crowded at the waiting areas due to the inefficient navigation scheduling has resulted in serious environment problems at the Three Gorges Dam, among which carbon emissions are the most focused one [2]. Hence, it is of importance to develop an advanced decision-support tool for the navigation scheduling in order to improve the effectiveness, efficiency and environmental performance of the overall lockage process at the Three Gorges Dam.

This paper investigates a green lock scheduling problem at the Three Gorges Dam, which is a complex decision-making problem involving both vessel scheduling problem and lock operation problem. The objective is to minimize the total carbon emissions of the overall lockage process, while at the same, improving the efficiency and fairness. First, taking into account of the maximum use of the chamber capacity, the vessels are assigned to different groups and the vessel sequence is then determined accordingly. After that, the vessels will travel from the waiting area to the lock chamber and their speeds have to be determined by the navigation scheduling.

In this paper, we use a mathematical programming approach in order to answer the following research questions:

- How can the carbon emissions related to the lockage process be reduced through an improved and green navigation scheduling at the Three Gorges Dam?

- Whether a green navigation scheduling can reduce the total waiting time and improve the overall efficiency.

The rest of this paper is organized as follows. Section 2 presents a literature review on vessel scheduling and lock scheduling problems. Section 3 gives the problem description. The mathematical model of the green ship lock scheduling problem is formulated in Section 4. Section 5 develops an algorithm to solve the proposed model. A numerical experiment is given in Section 6 in order to validate the proposed model and algorithm. Section 7 presents the results, discussion and managerial implications. Finally, Section 8 concludes the paper and gives suggestions for further research.

\section{Literature Review}

The green lock scheduling problem of the Three Gorges Dam is related to both vessel scheduling problem and lock scheduling problem, so this section presents a literature review on recent publications for both problems.

\subsection{Vessel Scheduling}

Vessel scheduling problem has been focused in many research works. Wang, et al. [3] investigated a mixed integer non-linear and non-convex problem for vessel scheduling problem with transit-time-sensitive demand. The objective is to maximize the overall profit generated in a ship route, and a branch-and-bound based algorithm is developed to solve the model. Agarwal and Science [4] developed a mixed integer linear programing model for the vessel scheduling and cargo routing problem. The model aims at maximizing the total profit. Three heuristics algorithm: greedy algorithm, column generation based algorithm and Benders decomposition based algorithm were tested and compared with respect to both the quality of solution and the computational performance. Considering the time window of the pickup and delivery of cargos, Christiansen and Fagerholt [5] formulated a robust vessel scheduling problem. Through implementing a penalty cost on inefficient operations (e.g., ship arrival at weekend), the robustness of the schedule can be improved with a sacrifice on the economic efficiency related to the transportation. Taken into account of the conflict 
between different cost components, Dulebenets [6] modelled a multi-objective mixed integer nonlinear program for the vessel scheduling problem, which accounted for all major route service cost components reported in the literature and separates them in two conflicting groups. The model was linearized by discretizing the vessel sailing speed reciprocal, and a Global Multi-Objective Optimization Algorithm was developed to solve the linearized model.

Venturini et al. [7] formulated an improved mathematical model for berth allocation problem (BAP) under an assumption of strong cooperation between shipping lines and container terminals, which minimizes the costs for both ship line companies and cargo terminals. Considering the uncertainty related to the arrival and handling times of vessels, Umang et al. [8] investigated a stochastic berth allocation problem with disruption. Their model aims at minimizing the total realized cost for updating the berthing schedule with a given baseline planning when disruptions occur. Dulebenets et al. [9] formulated a mixed integer linear program for improving the operational planning of a marine container terminal. The objective of the model is to minimize the total weighted vessel turnaround time and the total weighted vessel late departures. In order to solve the optimization problem, a self-adaptive evolutionary algorithm is also proposed in this paper. Focusing on the efficiency of the waterway traffic management, Lalla-Ruiz et al. [10] proposed a mathematical model for the waterway ship scheduling problem in order to minimize the total waiting time. The model was solved by a simulated annealing (SA) method with different greedy rules. Elwany et al. [11] developed a heuristics-based approach to optimize the berth allocation and crane assignment problem, which aims at minimizing both operational costs and service quality costs.

Li et al. [12] investigated a bi-objective berth and quay crane co-scheduling problem, which aims at simultaneously minimizing the additional trucking distance and the port time of vessels. The proposed mathematical model was solved by an improved particle swarm optimization (PSO). Zhen et al. [13] proposed an integer-programming model for optimizing the berth allocation and quay crane operations taking into account of tides and channel flow control constraints. Considering the uncertainty of different disruptions, i.e., arrival time of vessels, handling operations, equipment malfunction, etc., Xiang et al. [14] investigated an optimal reactive strategy for berth allocation and crane assignment. In their research, a mixed integer program is first formulated for determining the baseline schedule. A behavior perception-based disruption model is then given for the simulation of disruption, and a rolling horizon heuristic proposed for minimizing the recovery cost in the reactive strategy. Taking into account of the uncertainty related to the cost and market demand, Chuang et al. [15] formulated a fuzzy mathematical model for the scheduling and route planning of container ships. A genetic algorithm was developed to solve the proposed model.

Due to the increased concern and pressure from the public, the environmental problems from the waterway transportation have been increasingly focused by recent research works. In literature, the carbon emissions due to the fuel consumption in the vessel scheduling problem has been extensively investigated [16,17]. Dulebenets et al. [18] modelled a carbon-constrained green vessel scheduling problem with a mixed integer non-linear program. The model aims at minimizing the overall route service cost under the carbon emission requirement. Du et al. [19] proposed a mixed integer non-linear program for a berth allocation problem, which simultaneously takes into account of the minimization of both departure delay and carbon emissions from all vessels. Dulebenets [20] formulated a mixed integer non-linear mathematical model for the green vessel scheduling problem. The model aims at minimizing the total carbon emission costs related to the vessel operations in sea and at ports. Wang et al. [21] introduced two quadratic outer approximation methods in order to solve a generic function of fuel consumption rate in a more efficient manner. Bialystocki and Konovessis [22] investigated the correlations between the fuel consumption and vessel speed, and the research work analyses the major factors affecting the fuel consumption and carbon emissions. Based upon an extensive literature survey, Kontovas [23] proposed a conceptual framework for the green vessel routing and scheduling problem. The paper identified the critical factors that influence the estimation of fuel consumption and carbon 
emissions, and a generalized mathematical model was formulated for the optimization of the green routing and scheduling problem of maritime transportation.

\subsection{Lock Scheduling}

The capacity limitation of the ship lock is the bottleneck that has significant impact of the effectiveness and efficiency of a navigation scheduling in waterway transportation. Several research works have been conducted in order to improve the lock scheduling and operations. Passchyn et al. [24] proposed two mathematical programming models (time-index formulation and lockage-based formulation) for a scheduling problem of consecutive locks. The objective of the models is to minimize both flow time and carbon emissions of the lockage process. Ting and Schonfeld [25] performed an optimization of vessel speed before they entering the ship lock in order to reduce the fuel consumption. Taking into account of three control alternatives: Tow dispatching, speed control and combined control, Ting and Schonfeld [26] proposed three different heuristic algorithms to optimize the ship lock operations.

The scheduling problem of a lock chamber can be considered as a two-dimensional bin-packing problem, so the objective is to maximize the space utilization [27]. In this regard, Verstichel, et al. [28] formulated a mixed integer linear programming model for a general lock scheduling problem, which incorporates three sub models: vessel placement, chamber assignment, and operation scheduling, namely. The vessel placement in the lock chamber was formulated as a bin-packing problem. Ji et al. [29] proposed a multi-objective mixed integer non-linear program for the co-scheduling problem of both the Three Gorges Dam and Gezhouba Dam on Yangtze River. The model aims at minimizing the total tardiness of the vessels, while at the same time, maximizing the utilization of the lock chambers. An orthogonal design-based non-dominated sorting genetic algorithm III (ONSGA-III) was developed to solve the optimization problem. Yuan, et al. [30] formulated a mathematical model for the co-scheduling problem of the ship lock operation and water-land transshipment coordination. The problem consists of two layers, where the inner layer depicts a general lock scheduling problem and the outer layer formulates the water-land transshipment. A first-come-first-served (FCFS) logic is used in the inner layer, while a genetic operators based artificial bee colony (GB-ABC) method is developed for solving the optimization problem in the outer layer.

\subsection{Summary}

The green lock scheduling problem of the Three Gorges Dam aims at minimizing the total carbon emissions from all vessels in passing through the dam, while at the same time, the efficiency of the lockage process should be improved as well. Even if significant efforts have been made in dealing with both vessel scheduling and lock scheduling problems, the established mathematical models cannot fully address the characteristics of the green lock scheduling problem of the Three Gorges Dam. Hence, in order to fill the literature gap, we propose a new mixed integer non-linear program and the main contributions are summarized as follows.

- We proposed a new mathematical model for the green lock scheduling problem of the Three Gorges Dam in order to reduce the total carbon emissions and improve the lockage efficiency, fairness and economic performance.

- In the model formulation, we incorporate both vessel scheduling problem and lock scheduling problem in order to fully address the characteristics of the green lock scheduling problem of the Three Gorges Dam.

- We obtain managerial implications that can be adopted in order to improve the navigation scheduling at the Three Gorges Dam. 


\section{Problem Description}

The five-stage ship lock is the only available method for large vessels with the gross weight more than 3000 tones to pass through the Three Gorges Dam. The Three Gorges Dam is $185 \mathrm{~m}$ high with a water-level difference at $175 \mathrm{~m}$ on both side, and a general ship lock with $2-3$ lock chambers cannot overcome such a high water-level difference. Therefore, the ship lock at the Three Gorges Dam includes five lock chambers, the available area of each lock chamber is $280 \times 34 \times 5 \mathrm{~m}$ (length $\times$ width $\times$ minimum water depth on the ridge). There are two identical ship locks located at the northern end of the Three Gorges Dam in order to separate the vessels travelling on upstream direction (Northern ship lock) and downstream direction (Southern ship lock). In the five-stage ship lock, it takes approximately 30 min to bring two chambers to the same water level, after which the vessels will travel from one chamber to the next, and the total time needed to pass through the five-stage ship lock is around three hours. In comparison with this, however, the waiting time spent at the anchorage occupies a great share of the whole lockage process.

The green lock scheduling problem models a vessel sequence and lockage process for passing through the five-stage ship lock at the Three Gorges Dam, and the problem includes a number of vessels which can only be arranged once. The optimal scheduling of the vessel sequence and lockage process can reduce the total waiting time and carbon emissions, while at the same time, meet the carriers' excepted cost. Figure 1 illustrates the green lock scheduling problem at the Three Gorges Dam. As shown, the vessels are required to send the relevant information to the TGNA one day in advance, which includes the empty weight, load, length and width of the vessel, as well as the estimated arrival time. Based on this, the TGNA make a schedule of vessels for passing through the dam.

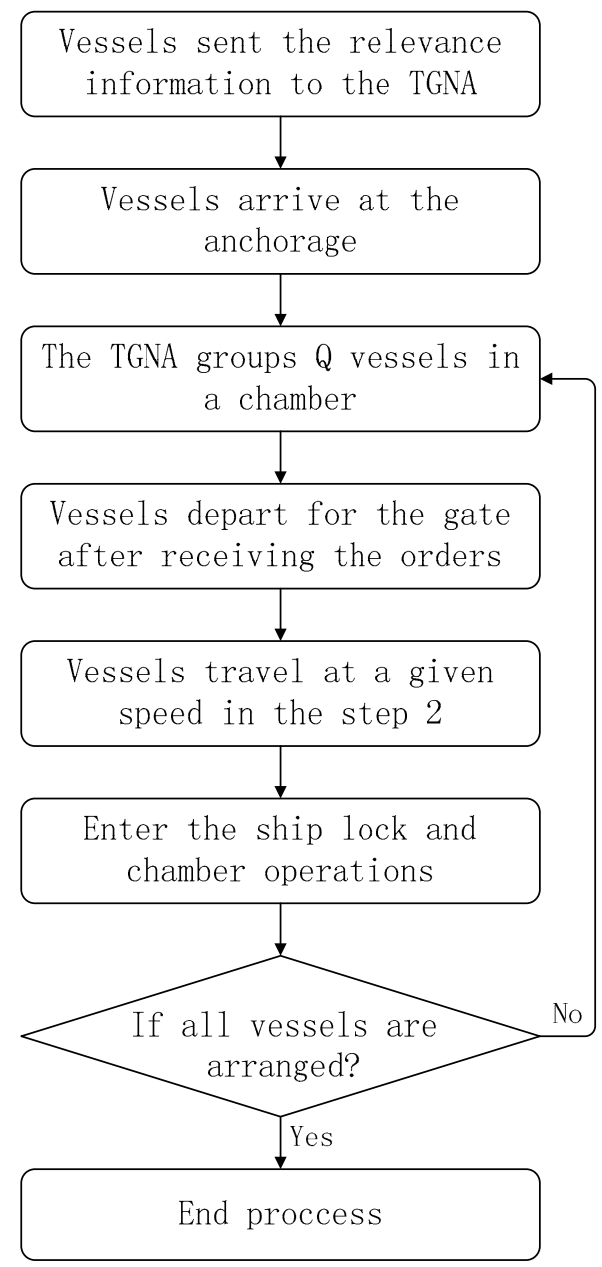

Figure 1. The green lock scheduling problem at the Three Gorges Dam. 
Figure 2 shows a simplified instance for vessels passing through the five-stage ship lock at the Three Gorges Dam, which includes 8 vessels with a waiting queue: $(1,2) \rightarrow(3,4) \rightarrow(5,6) \rightarrow(7,8)$. There are three steps for the vessels to pass through the five-stage ship lock at the Three Gorges Dam. First, the vessels arrived have to park at the anchorage waiting for the further arrangement. After the vessels receive the order from the TGNA, they will travel from the anchorage to the gate of the first lock chamber in the second step, and the travel distance is approximately $10 \mathrm{~km}$. Finally, the vessels will pass through the five chambers at different levels one by one.
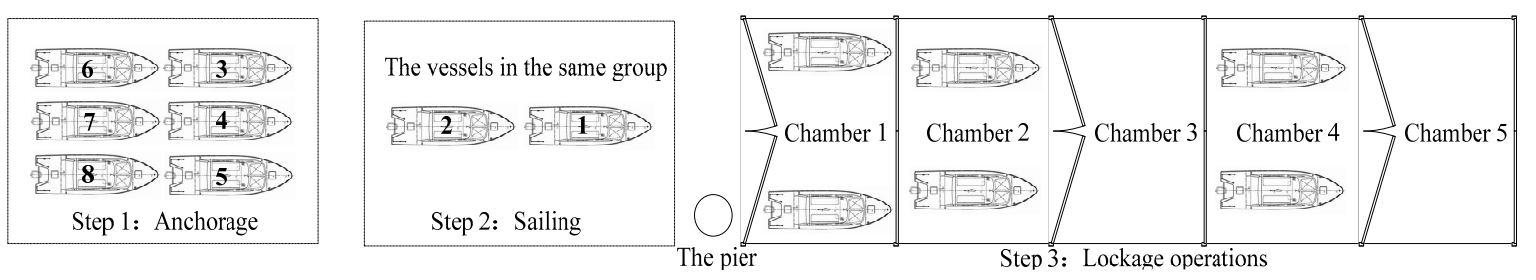

Figure 2. A simplified instance of vessel sequence and lockage process at the Three Gorges Dam (Northern ship lock).

Currently, there are several challenges related to the scheduling and planning of the vessel sequence and lockage process at the Three Gorges Dam. For example, in the second step, the TGNA request the vessels to have a relatively high speed in order to reach the gate of the first chamber in a short time and improve the lockage efficiency. However, the lockage efficiency is determined by the operation of the ship lock as well. When the first lock chamber is in operation, the arrived vessels cannot enter into it and thus have to wait at the pier, which is $500 \mathrm{~m}$ away from the first lock chamber. Facts have shown that the high vessel speed required in the second step has not improved the overall efficiency of vessels in passing through the five-stage ship lock due to the time-consuming chamber operations, but it only results in an increased amount of vessels waiting in the pier.

Another challenge is related to the priority of vessels in passing through the ship lock of the Three Gorges Dam. Under the present scheduling regulation, the vessel weight permitted ranges from 3000 to 7000 tones, and different priorities are given primarily based upon the vessel weight. The vessels with a lower weight is prioritized in passing through the ship lock, and most of the high-weighted cargo vessels are arranged in the end of the sequence. Nevertheless, the vessel weight is a critical parameter for fuel consumption even when the vessels are parked at the anchorage [31], and due to the long waiting time, the high-weighted cargo vessels not only have a higher fuel consumption but also result in a higher cost and more carbon emissions.

At the surrounding areas of the Three Gorges Dam, environmental impacts have been generated by the vessels in both waiting and lockage processes [32], among which the carbon emissions and domestic sewage are the most serious ones. In recent years, the air pollution in a nearby city: Yichang has becoming increasingly serious, one of the most important reasons is the carbon emissions as well as the emissions of other contaminants from the dramatically increased waterway transportation on Yangzi River. Further, due to the geographic condition and static wind frequency in the dam area, those contaminants cannot be easily spread and diffused. Besides, the domestic sewage discharged by the vessels waiting at the anchorage also has a negative impact on the water quality at the dam area.

Therefore, it is of vital importance for the TGNA to improve the scheduling and planning of the vessel sequence and lockage operations in order to minimize the waiting time and carbon emissions under the constraint of economic performance, and improve the overall efficiency.

\section{Mathematical Model}

\subsection{Fuel Consumption}

Fuel consumption are influenced by many factors among which the speed and payload of the vessel play the most important roles. In estimating the fuel consumption of a vessel, a frequently used 
formula is given in $f(v)=k v^{3}$ [17], where the fuel consumption of vessels is directly proportional to the speed cubed [33]. Nevertheless, this cubic relationship has been criticized by many researchers due to its incapability in performing an accurate estimation of fuel consumption when the speed of vessels is low [23]. In fact, there may also be a large fuel consumption when the vessels travel in low speed or park at the anchorage, and in those cases, the fuel consumption is still positively correlated to the payload and weight of the vessel if empty [31]. In order to obtain more accurate estimation on the fuel consumption of vessels, Equation (1) formulated by Kontovas [23] is employed.

$$
f\left(v_{i}, w_{i}\right)=k\left(p+v_{i}^{q}\right)\left(a_{i}+w_{i}\right)^{2 / 3}
$$

where:

$v_{i}$-Speed of vessel $i$ (kilometer per hour);

$w_{i}$-Payload of vessel $i$ (tonnes);

$a_{i}$-The weight of the vessel $i$ if empty (tonnes);

$k, p, q$-Constants, and $k>0, p \geq 0$ and $q \geq 3$.

In Equation (1), $k$ is the ship-specific constant which is related to the ship's characteristics and loading conditions [23], and $p$ is used to adjust the calculation of the fuel consumption when the vessel speed is low. In this paper, when the vessel waits for the order from the TGNA at the anchorage, the fuel consumption can be estimated using Equation (2).

$$
F_{1}^{i}=k p\left(w_{i}+a_{i}\right)^{2 / 3}
$$

where:

$F_{i}^{1}$-The daily fuel consumption of vessel $i$ in step 1 (tonnes/day).

$F_{i}^{1}$ calculates the fuel consumption for maintaining the steady state of the vessel on the water, generating electricity for people living on board, and so forth. When the vessel travels in step 2 , the fuel consumption can be calculated in Equation (3).

$$
F_{2}^{i}=k\left(p+v_{i}^{3}\right)\left(a_{i}+w_{i}\right)^{2 / 3}
$$

where:

$F_{i f}^{2}-$ The daily fuel consumption of vessel $i$ in step 2 (tonnes/day);

The formula is suitable for estimating the fuel consumption of large and medium-sized vessels when $q=3$ [34]. In order to simplify the modelling of the problem, some other factors may affect the fuel consumption of vessels, i.e., weather condition, are not taken into consideration in this paper.

\subsection{Carbon Emissions}

Waterway transportation generates several environmental impacts among which the carbon emissions from vessels is one of the most significant issues [19]. The carbon emissions from vessels are related to the fuel consumption and the carbon fraction in the fuel, and this relationship can be used to calculate the rate of carbon emission [35], as shown in Equation (4). The proportionality between the fuel consumption and carbon emissions is called "carbon coefficient" [17]. In accordance with IMO 2019 [36], the carbon coefficient is 3.082 (tonnes of carbon emissions per tonne of fuel consumption).

$$
C E_{i}=\alpha_{c O_{2}} \times k\left(p+v_{i}^{3}\right)\left(a_{i}+w_{i}\right)^{2 / 3}
$$

where:

$C E_{i}$ - the carbon emissions of vessel $i$ (tonnes/day);

$\alpha_{\mathrm{CO}_{2}}$ - carbon coefficient. 


\subsection{Chamber Capacity and Vessel Arrangement}

The chamber capacity and vessel arrangement in the chambers are of great importance in the lock scheduling problem of the Three Gorges Dam. The operation of the lock chambers is not continuous, and it takes time to bring the water of two adjacent chambers to the same level when the gate is closed. In order to improve the usage of chamber space and overall operational efficiency of the lockage process, inspired by Yuan et al. [30], we simplified and formulated the chamber capacity and vessel arrangement in the chamber as a two-dimensional bin-packing problem in this paper. For two connecting vessels in sequence departed from the anchorage, two scenarios are existed. First, the two vessels are arranged in the same group of departure and will be placed in the same chamber when passing through the five-stage ship lock. The other scenario is, due to the limitation of chamber capacity, two connecting vessels in sequence are arranged in two different groups and will be placed in two separate chambers. In the latter case, the interval of the scheduled departure time for those two vessels should be larger than the chamber operation time, which means the succeeding vessels should wait at the anchorage.

When several vessels are assigned to the same chamber in the lockage process, the chamber capacity requirement should be met. As shown Figure 3a, the sum of the length and width cannot exceed the safety area on both sides of a chamber. Constraint (5) guarantees the arrangement of the vessels in each chamber fulfills the capacity requirement throughout the lockage process. In addition, Equation (6) is formulated to determine the specific positions of the vessels in the same chamber so that they will not be overlapped with each other. In constraint (6), the first formula determines if vessel $i$ is placed in front of vessel $j$; the second one determines if vessel $i$ is placed behind of vessel $j$; the third one determines if vessel $i$ is placed in the left of vessel $j$; and the forth one determines if vessel $i$ is placed in the right of vessel $j$. Figure $3 \mathrm{~b}$ shows vessel $i$ is placed in the front of vessel $j$ as well as the overlap occurred in the left of vessel $j$.

$$
\begin{gathered}
\left\{\begin{array}{l}
0 \leq G_{f}^{i} \times x_{i} \leq G_{f}^{i}\left(L_{2}-l_{i}\right) \\
0 \leq G_{f}^{i} \times y_{i} \leq G_{f}^{i}\left(D_{2}-d_{i}\right)
\end{array}, \forall i \in S, \forall f \in F\right. \\
\left\{\begin{array}{l}
G_{f}^{i} \times G_{f}^{j} \times\left(x_{j}+l_{j}-x_{i}\right) \leq 0 \\
G_{f}^{i} \times G_{f}^{j} \times\left(x_{i}+l_{i}-x_{j}\right) \leq 0 \\
G_{f}^{i} \times G_{f}^{j} \times\left(y_{j}+d_{j}-y_{i}\right) \leq 0 \\
G_{f}^{i} \times G_{f}^{j} \times\left(y_{i}+d_{i}-y_{j}\right) \leq 0
\end{array}, \forall i, j \in S, \forall f \in F\right.
\end{gathered}
$$

where:

$G_{f}^{i}$-Binary variable, if $G_{f}^{i}=1$, vessel $i$ is in chamber $f$, and $G_{f}^{i}=0$ otherwise;

$x_{i}, y_{i}$-Variables that define the $x$ and $y$ position of vessel $i$ in the chamber;

$l_{i}, d_{i}$-Length and width of vessel $i$ (meter);

$D_{2}, L_{2}$ - Length and width of the lock chamber (meter).

Using the auxiliary function given in Equation (7), Equation (6) is simplified and re-formulated in Equation (8).

$$
\begin{gathered}
\Phi(x)=\left\{\begin{array}{l}
0, x \leq 0 \\
1, x>0
\end{array}\right. \\
B_{f}^{i} \times B_{f}^{j} \times \Phi\left(x_{j}+l_{j}-x_{i}\right) \times \Phi\left(x_{i}+l_{i}-x_{j}\right) \times \\
\Phi\left(y_{j}+d_{j}-y_{i}\right) \times \Phi\left(y_{i}+d_{i}-y_{j}\right) \leq 0, \forall i, j \in S, \forall f \in F
\end{gathered}
$$

Due to the different sizes of difference vessels, the number of vessels assigned to one group is by no means identical. In this paper, $Q_{f}$ is used to represent the number of vessels in chamber $f$, which decides the dimension of the particle in particle swarm optimization (PSO). 


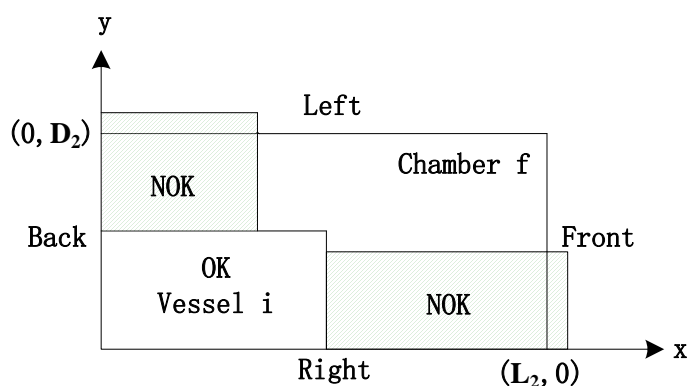

(a) the area of vessel cannot exceed the chamberEquation (5)

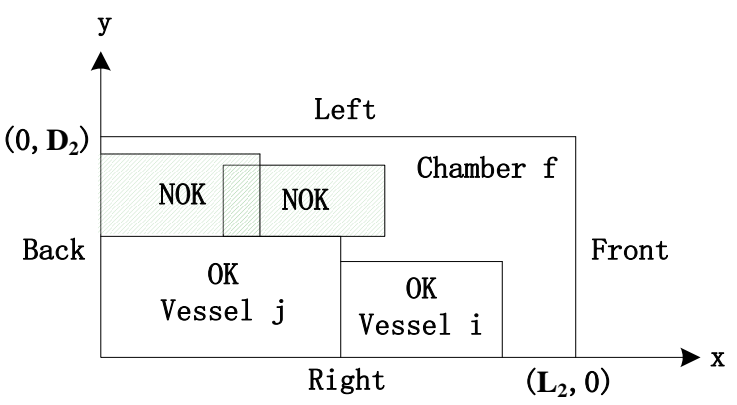

(b) the placement of two adjacent vessels-Equation

(6) to Equation (8)

Figure 3. Constraints for vessels placement.

\subsection{Expected Cost}

The cost of vessels associated with passing through the Three Gorges Dam comprises of two parts: conventional cost and delay penalty, respectively. Conventional cost includes fuel cost as well as additional cost in waiting, i.e., the cost related to the damage to goods in transit, etc. [37]. The fuel cost is proportional to the fuel consumption of vessels in passing through the dam, and the additional cost in waiting is proportional to the waiting time in the anchorage. In order to meet the carriers' expectation on both fuel cost and additional cost in waiting, Equations (9) and (10) are formulated as follows.

$$
\begin{gathered}
\left(F_{1}^{i} \times t_{i}^{b e r}+F_{2}^{i} \times L_{1} / v_{i}\right) P_{1}=C_{i 1} \\
\left(R T_{i}^{D}-R T_{i}^{A}\right) P_{2}=C_{i 2}
\end{gathered}
$$

where:

$P_{1}$-Cost of fuel per unit (CNY/tonne);

$\mathrm{P}_{2}$-Multiplier of the additional cost in waiting (CNY/hour);

$C_{i 1}$-Expected fuel cost of carrier $i(\mathrm{CNY})$;

$C_{i 2}$-Expected additional cost of carrier $i$ in waiting (CNY);

$R T_{i}^{A}$ - Real arrival time of vessel $i$ at the anchorage;

$R T_{i}^{D}$ - Real departure time of vessel $i$ from the anchorage.

The second part is the delay penalty, which aims at regulating the carriers' behaviors in order to guarantee the navigation efficiency. This penalty is imposed by the TGNA to two types of delay: arrival delay and departure delay. The arrival delay penalty [30] is implemented for the long delay of a vessel in arriving at the anchorage in comparison with the reported arrival time to the TGNA, and this may affect the pre-determined navigation scheduling based upon the information submitted by the vessels. The departure delay penalty $\left(P_{D}\right)$ is implemented for the delay on departure of vessels parking at the anchorage after an order has been given by the TGNA, and this may influence the planning of the lockage operations. Compared with the arrival delay, the influence of the departure delay on the overall efficiency of the navigation scheduling and the lockage operations is much more serious, so the penalty on the departure delay should be higher than that of the arrival delay.

$$
\begin{gathered}
P_{A}\left(R T_{i}^{A}-P T_{i}^{A}\right)=C_{i 3} \\
P_{D}\left(R T_{i}^{D}-D T_{i}^{D}\right)=C_{i 4} \\
\sum_{m=1}^{4} C_{i m} \leq \text { Expected cost } t_{i}, \forall i \in S
\end{gathered}
$$

where: 
$P_{A}$-Arrival delay penalty per unit (CNY/hour);

$P_{D}$-Departure delay penalty per unit (CNY/hour);

$C_{i 3}$-Expected arrival delay of carrier $i(\mathrm{CNY})$;

$C_{i 4}$-Expected departure delay of carrier $i(\mathrm{CNY})$;

$P T_{i}^{A}$-Estimated arrival time of vessel $i$ at the anchorage;

$D T_{I}^{D}$-Scheduled departure time of vessel $i$ from the anchorage

Expected cost $t_{i}$-Total expected cost of carrier $i(\mathrm{CNY})$.

\subsection{The Mathematical Model for Green Lock Scheduling Problem}

The green lock scheduling problem of the Three Gorges Dam combines both vessel scheduling and lock scheduling problems, while at the same time, taking into consideration of the environmental impact. Through the optimization of vessel speed and scheduling of the lockage operations, the proposed mathematical model aims at minimizing the total carbon emissions from all vessels in passing through the Three Gorges Dam under several constraints, i.e., economic performance, capacity limitation, etc.

The decision variables, sets and parameters in the mathematical model are first given as follows.

\section{Decision variables:}

$v_{i} \quad$ Speed of vessel $i .(\mathrm{km} /$ hour $)$

$K_{i j} \quad$ Binary variable, if $K_{i j}=1$, vessel $i$ directly follows vessel $j$, and $K_{i j}=0$

Otherwise.

$G_{f}^{i} \quad$ Binary variable, if $G_{f}^{i}=1$, vessel $i$ is in chamber $f$, and $G_{f}^{i}=0$ otherwise.

$D T_{i}^{D} \quad$ Scheduled departure time of vessel $i$ from the anchorage. (hour)

$S C_{1}^{i} \quad$ Scheduled time for vessel $i$ in the first chamber. (hour)

\section{Sets and Parameters:}

$S \quad$ Set of vessels scheduled on a daily basis, $i, j \in S$

$N_{S} \quad$ Number of elements in set $S$

$F \quad$ Set of chambers, $f \in F$

$W_{i} \quad$ The total weight of vessel $i$. (tonnes)

$F_{3}^{i} \quad$ The daily fuel consumption of vessel $i$ in chamber. (tonnes/day)

$T C_{f}^{i} \quad$ Real time for vessel $i$ in chamber $f$. (hour)

$T_{\text {start }} \quad$ Starting time of navigation scheduling. (hour)

$T_{\text {end }} \quad$ Required end time of the scheduling period. (hour)

$t_{r} \quad$ Upper limit of waiting time at anchorage. (hours)

$t_{i}^{b e r} \quad$ The waiting time of vessel $i$ at the anchorage. (hours)

$t_{1} \quad$ Overall operation time in a chamber. (hours)

$L_{1} \quad$ Distance from the anchorage to the pier. $(\mathrm{km})$

$v_{2} \quad$ Limited speed in the lock chamber. ( $\mathrm{km} /$ hour)

$U \quad$ A constant specifying the relationship between weight and speed of a vessel

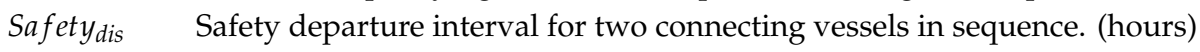

The mathematical model of the green lock scheduling problem of the Three Gorges Dam is formulated as follows.

$$
\begin{gathered}
\min =\sum_{i \in S} \alpha_{c o_{2}}\left(F_{1}^{i} \times\left[t_{i}^{b e r}+5\left(t_{1}-L_{2} / v_{2}\right)\right]+F_{2}^{i} \times\left(L_{1}+0.5\right) / v_{i}+5 F_{3}^{i} \times L_{2} / v_{2}\right\} / 24 \\
F_{3}^{i}=k\left(p+v_{2}^{3}\right)\left(a_{i}+w_{i}\right)^{\frac{2}{3}}
\end{gathered}
$$

Subject to:

$$
\sum_{j \in S} K_{i j}=1, \forall i \in S \cap i \neq j
$$




$$
\begin{aligned}
& \sum_{i \in S} \sum_{j \in S} K_{i j}=N_{S}-1 \\
& D T_{j}^{D}-\sum_{i \in S} K_{i j} \times D T_{i}^{D} \geq \max \left\{t_{1} \times\left(1-G_{1}^{j}\right), \text { Safety }_{\text {dis }}\right\}, \forall i \in S \cap i \neq j \\
& R T_{i}^{D}-R T_{i}^{A}=t_{i}^{b e r}, \forall i \in S \\
& 0 \leq t_{i}^{b e r} \leq t_{r}, \forall i \in S \\
& K_{i j} \times R T_{i}^{A} \leq R T_{j}^{A}, \forall i, j \in S \\
& R T_{i}^{A} \geq P T_{i}^{A}, \forall i \in S \\
& D T_{i}^{D} \geq R T_{i}^{A}, \forall i \in S \\
& R T_{i}^{D} \geq D T_{i}^{D}, \forall i \in S \\
& L_{1} / v_{i} \leq 5 t_{1}, \forall i \in S \\
& v_{i} \times W_{i} \leq \mathrm{U}, \forall i \in S \\
& S C_{1}^{i} \geq R T_{i}^{D}+L_{1} / v_{1}, \forall i \in S \\
& T C_{1}^{i} \geq S C_{1}^{i}, \forall i \in S \\
& T C_{f+n}^{i}-T C_{f}^{i} \geq n t_{1}, \forall i \in S, f \in F \cap f+n \leq 5 \\
& S C_{1}^{j}-\sum_{i \in S} K_{i j} \times S C_{1}^{i} \geq \max \left\{t_{1} \times\left(1-G_{1}^{j}\right), \text { Safetydis }\right\}, \forall i \in S \cap i \neq j \\
& T C_{f+1}^{j}-\sum_{i \in S} K_{i j} \times T C_{f}^{i} \geq \max \left\{t_{1} \times\left(1-G_{f}^{j}\right), \text { Safety }_{\text {dis }}\right\}, \forall i \in S \cap i \neq j, f \in F \cap f+n \leq 5 \\
& \sum_{i \in S} \sum_{f \in F} G_{f}^{i}=5 N_{S} \\
& T C_{1}^{N_{S}}+5 t_{1} \geq T_{\text {end }} \\
& D T_{1}^{D} \geq T_{\text {start }}
\end{aligned}
$$

The objective function Equation (14) minimizes the total carbon emissions generated from all vessels in passing through the dam. Constraints (15) determine the sequence of the vessels in the navigation scheduling, and constraint (16) ensures that all the vessels are scheduled within the given period. Constraints (17) guarantee the scheduled departure time between two connecting vessels in sequence is larger than the safety interval if they are arranged to the same group for passing through the five-stage ship lock. When two connecting vessels are assigned to different groups due to the capacity limitation of the ship lock, the scheduled departure time between them should be larger than the chamber operation time. Constraints (18) calculate the waiting time for vessel $i$ at the anchorage. Constraints (19) require the waiting time of a vessel at the anchorage cannot be longer than the upper limit. Constraints (20) ensure fairness between the scheduled vessels with real arrival times at the anchorage. Constraints (21)-(23) specify the relationships among estimated arrival time, real arrival time, scheduled departure time and real departure time. Constraints (24) set a limit on the vessel speed in step 2, and Constraints (25) give a relationship between the total weight and speed of vessels in step 2. Constraints (26) ensure the scheduled time of vessel $i$ to enter the first lock chamber cannot be earlier than its arrival time to the pier. Constraints (27) and (28) are the restrictions on the start time for vessel $i$ in chamber $f$. Constraints (29) and (30) ensure both the capacity requirement of lock chamber and the safety distance requirement for two connecting vessels in sequence are fulfilled in the lockage process. Constraint (31) ensures all vessels to be scheduled will pass through the five-stage ship lock 
at the Three Gorges Dam. Constraint (32) guarantees the last vessel within set $\mathrm{S}$ should be able to pass through the ship lock before the latest finish time of the given period. Constraint (33) ensures the scheduled departure time of the first vessel within the set $S$ should not be earlier than the earliest start of the given period. In addition, the decision variables should fulfill their respective binary or non-negative requirements, and the capacity requirements of the lock chamber given in Section 4.3 should always be satisfied. In some cases, the constraints of economic performance formulated in Section 4.4 should also be taken into account.

\section{Solution Approach}

The proposed mathematical model combines both vessel scheduling and lock scheduling problems and is formulated as a mixed integer non-linear program. Moreover, it is a NP-hard problem and thus requires significant computational efforts. Due to this reason, exact method can only be used when the size of problem is very small. For solving large-scale problems in the real world, heuristics as well as other approximation methods should be used in order to improve the computational efficiency. In this paper, we employed a greedy-particle swarm optimization (G-PSO) method to solve the optimization problem, and it combines both the greedy algorithm and particle swarm optimization (PSO).

\subsection{Greedy Algorithm}

Greedy algorithm is a heuristic that aims at approximating the global optimum through a step-by-step search and selection of the local optimum. It searches the domain of feasible solution with a pre-defined rule determining which elements should be selected to the solution at each stage, and the algorithm stops while optimal solutions at all stages of the problem are found. Due to its simplicity of implementation, greedy algorithm has been used to solve a large variety of complex optimization problems. The most important step of using a greedy algorithm is to design the rule for selecting the best solution at each stage, and the rules are by no means identical for different problems.

In this paper, greedy algorithm is applied to determine the vessel sequence in passing through the Three Gorges Dam. The principle of the sequence design is to minimize the overall waiting time of the vessels so that the carbon emission in step 1 can be reduced and the efficiency of navigation scheduling can be improved. Besides, with the help of the maximum waiting time constraint, the rule of first-come-first-served (FCFS) [38] is implemented in the greedy algorithm in order to improve the efficiency of the navigation scheduling at the Three Gorges Dam. This rule has been widely adopted in many waterway transportation facilities $[7,39,40]$, with which the sequence of vessels are given based on their arrival time and waiting time at the anchorage. In brief, FCFS requires the priority in passing through the dam is given to the vessels with the earliest arrival time at the anchorage regardless of their weights, and the waiting time requirement for each vessel should be fulfilled. Therefore, this rule can also improve the fairness of the navigation scheduling by taking the arrival time as the most predominant factor for determining the vessel sequence in Step 2.

\subsection{Particle Swarm Optimization (PSO)}

The particle swarm optimization (PSO) is a meta-heuristic for approximating an optimal solution of a complex optimization problem. PSO is an evolutionary algorithm that mimics the clustering behavior of animals, e.g., insect flocking, fish schooling, etc. In the natural world, animal groups usually search for food in a cooperative way. Each member of the group constantly improves its searching pattern by learning from its own experience and also from the experience of the other members [41].

When implementing PSO to solve complicated optimization problems, a set of feasible solutions are randomly generated in the initial step. Each feasible solution in PSO is considered as a particle of a $n$-dimensional search space, and the position and velocity of a particle $i$ is expressed as $X_{i}=\left(x_{i, 1}, x_{i, 2}\right.$, $\left.\ldots, x_{i, Q f}\right)$ and $V_{i}=\left(v_{i, 1}, v_{i, 2}, \ldots, v_{i, Q f}\right)$. Each particle has their fitness that is determined by the objective function. The fitness measures the distance between the position of the particle and the current best position in the search space identified by other particles. In each iteration, a particle knows the best 
position in the search space (a local optimum) and its current position, based on which it determines the next movement towards the local optimum. The mathematical model depicting the movement of particles is given as follows [42]:

$$
\begin{gathered}
v_{i, j}(t+1)=w v_{i, j}(t)+c_{1} r_{1}\left[p_{i, j}-x_{i, j}(t)\right]+c_{2} r_{2}\left[p_{g, j}-x_{i, j}(t)\right] \\
x_{i, j}(t+1)=x_{i, j}+v_{i, j}(t+1), j=1,2, \ldots, Q_{f}
\end{gathered}
$$

where:

$p_{i, j}$-Maximum fitness value of the individual $i$;

$p_{g, j}$-Maximum fitness value of the whole population;

$w$-Inertia weight;

$c_{1}, c_{2}$-Positive learning factor;

$r_{1}, r_{2}$-Uniformly distributed random numbers between 0 and 1 .

The local optimum is updated when a better position is found in the search space, and the solution found is improved. Through several iterations, the optimal solution is approximated through the swarm movement towards the best position.

\subsection{Greedy-Particle Swarm Optimization (G-PSO)}

In this paper, the greedy algorithm is used as the first step of the G-PSO algorithm, which determines the sequence of vessels in passing through the Three Gorges Dam. It forms the basis for implementing the PSO method. After the vessel sequence is given, the number of vessels in the same chamber specifies the dimension of the search space, and the particles are generated in order to determine the optimal speed of each vessel in step 2. The schematic of the G-PSO algorithm for solving the proposed model is given in Figure 4.

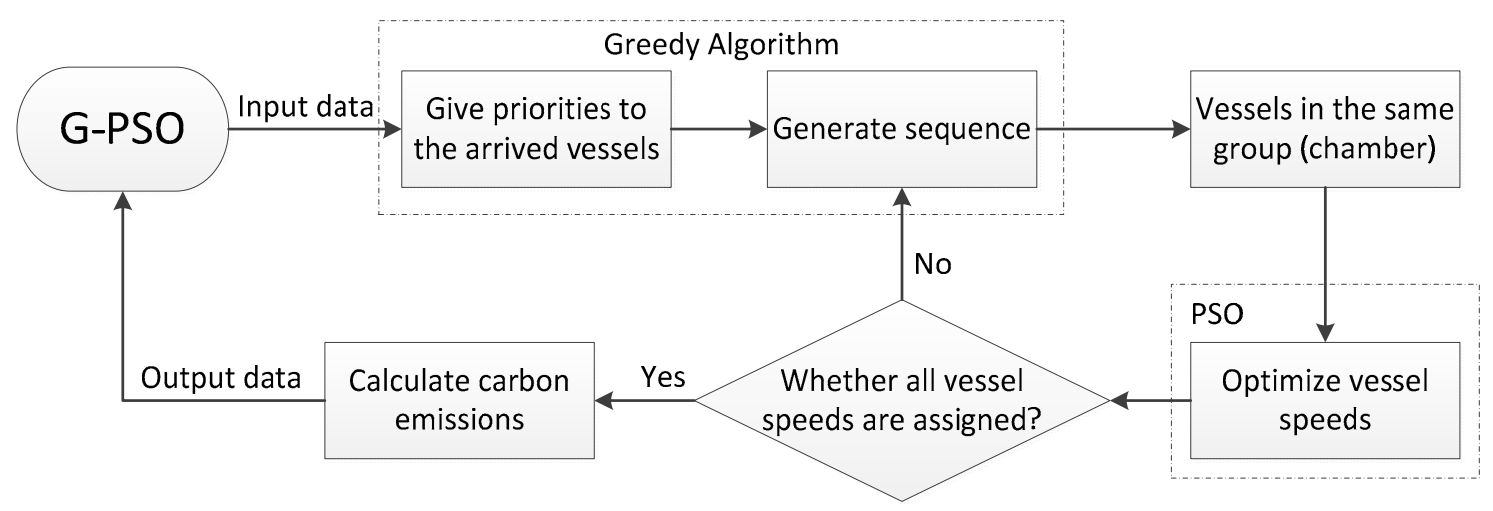

Figure 4. The G-PSO algorithm.

\section{Numerical Experiments}

This section presents the numerical experiments in order to show the applications of the proposed mathematical model and solution approach for the green lock scheduling problem of the Three Gorges Dam. For simplicity sake, only the scheduling problem of one direction (southern ship lock) is tested in the numerical experiments. The operations and navigation scheduling of the other direction is identical. At present time, the delay penalties have not been implemented by the TGNA. When delay occurs in arrival or departure, a verbal warning will be given to the vessels. Hence, in the numerical experiments, we simplified the problem by requiring all vessels are arrived at and departed from the anchorage on time. In addition, in the scheduling of the lock chamber operations, the loop will be jumped out when the chamber capacity requirement cannot be satisfied, say, a departure demand can be given to a vessel only when it can be handled by the ship lock in a timely fashion. 
In accordance with Ji et al. [29], the numerical experiments take 40 vessels into the optimization on a daily basis. The parameters related to the 40 vessels were randomly generated by MATLAB 2016a. At the Three Gorges Dam, the vessels under 3000 tones can use the ship lift to pass through the dam, so the weight range for vessels using the five-stage ship lock is set to [3000, 7000] tones. In the numerical experiments, the weight of 25 vessels is between 3000 and 5000 tones, and the weight range of the other vessels is from 5000 to 7000 tones. Table 1 presents the parameters used in the numerical experiments. The vessel arrival times are randomly generated within $24 \mathrm{~h}$. Moreover, considering the route capacity, the safety interval is set to $5 \mathrm{~min}$ for two connecting vessels in sequence. In the lockage process, the average speed is $2.16 \mathrm{~km} / \mathrm{h}$, and the minimum interval between two groups of vessels is $1 \mathrm{~h}$. After a number of experiments with rational convergence rate and speed of the algorithm, we obtained a set of reliable input parameters for the G-PSO algorithm. The particle group consists of 200 particles; both positive learning factors $\left(c_{1}, c_{2}\right)$ are 2; the number of iterations $(t)$ is 100; and the inertia weight $(w)$ is 0.5 .

The program is coded and run in MATLAB 2016a, and the average running time is $3 \mathrm{~s}$. With the result of FCFS-greedy, PSO has been run for nine times in order to finish the optimization of the 40 vessels.

Table 1. Parameters used in the numerical experiment.

\begin{tabular}{|c|c|c|c|c|}
\hline Number & Arrival Time (hh:mm:ss) & Weight (Tonnes) & Length (Meter) & Width (Meter) \\
\hline 1 & 00:33:00 & 3878 & 56 & 25 \\
\hline 2 & 01:55:00 & 4894 & 56 & 26 \\
\hline 3 & 02:03:00 & 6496 & 60 & 38 \\
\hline 4 & 02:22:00 & 3985 & 56 & 27 \\
\hline 5 & 02:26:00 & 6317 & 60 & 32 \\
\hline 6 & 04:08:00 & 4019 & 54 & 28 \\
\hline 7 & 04:24:00 & 4906 & 57 & 23 \\
\hline 8 & 04:29:00 & 6465 & 59 & 39 \\
\hline 9 & 05:51:00 & 4881 & 56 & 20 \\
\hline 10 & 05:54:00 & 6392 & 56 & 30 \\
\hline 11 & 06:14:00 & 6457 & 60 & 38 \\
\hline 12 & 07:21:00 & 6489 & 65 & 49 \\
\hline 13 & 07:49:00 & 3709 & 56 & 22 \\
\hline 14 & 08:08:00 & 3739 & 56 & 32 \\
\hline 15 & 08:10:00 & 3599 & 56 & 31 \\
\hline 16 & 09:16:00 & 3983 & 56 & 23 \\
\hline 17 & 10:07:00 & 3972 & 57 & 21 \\
\hline 18 & $10: 25: 00$ & 4917 & 59 & 24 \\
\hline 19 & 11:11:00 & 3853 & 56 & 32 \\
\hline 20 & 12:11:00 & 6322 & 58 & 42 \\
\hline 21 & $12: 20: 00$ & 6421 & 65 & 41 \\
\hline 22 & $12: 31: 00$ & 6496 & 58 & 26 \\
\hline 23 & 13:00:00 & 3672 & 55 & 33 \\
\hline 24 & $13: 46: 00$ & 5884 & 65 & 38 \\
\hline 25 & 13:48:00 & 3883 & 56 & 29 \\
\hline 26 & $14: 05: 00$ & 4904 & 57 & 32 \\
\hline 27 & $14: 52: 00$ & 5740 & 57 & 19 \\
\hline 28 & $15: 07: 00$ & 3658 & 55 & 29 \\
\hline 29 & $16: 11: 00$ & 4948 & 57 & 27 \\
\hline 30 & $17: 05: 00$ & 4746 & 56 & 31 \\
\hline 31 & $17: 14: 00$ & 5854 & 66 & 44 \\
\hline 32 & $17: 24: 00$ & 6265 & 68 & 44 \\
\hline 33 & $18: 16: 00$ & 5918 & 58 & 38 \\
\hline 34 & 19:37:00 & 4899 & 56 & 36 \\
\hline 35 & 19:41:00 & 5848 & 58 & 25 \\
\hline 36 & $19: 58: 00$ & 3727 & 65 & 44 \\
\hline 37 & 21:09:00 & 3620 & 55 & 21 \\
\hline 38 & 21:49:00 & 4919 & 58 & 30 \\
\hline 39 & 21:57:00 & 3986 & 56 & 24 \\
\hline 40 & 22:04:00 & 4997 & 58 & 33 \\
\hline
\end{tabular}




\section{Result and Discussion}

The primary objective of the proposed mathematical model and algorithm is to reduce the overall carbon emissions from all vessels in passing through the Three Gorges Dam. In the current navigation scheduling, the vessels are required to sail at a high speed in step 2 in order to reduce the number of vessels crowded at the anchorage and improve the efficiency in the lockage process, but this has led to a longer waiting time at the pier due to the capacity limitation of the lock chamber. Another problem is that, in accordance with the current regulation of navigation scheduling, low-weight vessels get priority in passing through the dam, and this has resulted in a long waiting time of high-weight vessels at the anchorage and more carbon emissions as well as other environmental impacts. Thus, we are interested in how the current navigation scheduling can be improved through both speed adjustment and reduction of waiting time in order to minimize the overall carbon emissions.

The comparison of the original navigation scheduling and the optimized navigation scheduling are given in Tables 2 and 3, respectively. It is observed that the vessels with lower weight get priority in the original navigation scheduling, but in the optimized navigation scheduling, the sequence is determined only by the arrival time of the vessels. The lockage process starts immediately when all the vessels in the same group have arrived at the pier. Due to the standard operational procedures implemented, the lockage time of the five-stage ship lock is set to $3 \mathrm{~h}$. In both navigation scheduling, the five-stage ship lock have to be operated for eight times in order to ensure all the 40 vessels to pass through the dam. In the original navigation scheduling, the total operating time of the ship lock is $22.27 \mathrm{~h}$, while it increases to $25.45 \mathrm{~h}$ in the optimized navigation scheduling.

Table 2. Comparison of the vessel sequence, the departure time from the anchorage, the arrival time at the pier and the waiting time at the anchorage of each vessel in both original navigation scheduling and optimized navigation scheduling.

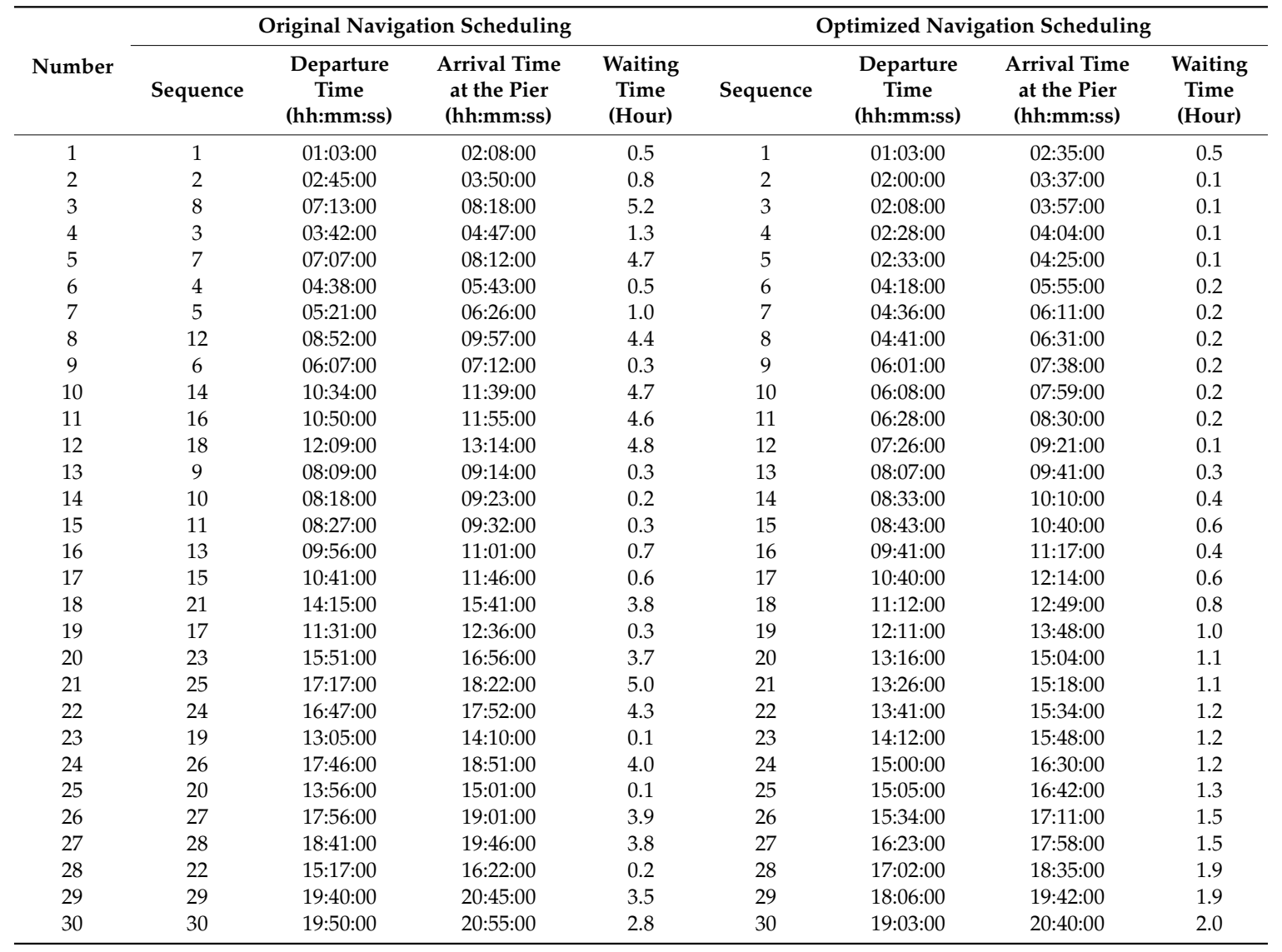


Table 2. Cont.

\begin{tabular}{|c|c|c|c|c|c|c|c|c|}
\hline \multirow[b]{2}{*}{ Number } & \multicolumn{4}{|c|}{ Original Navigation Scheduling } & \multicolumn{4}{|c|}{ Optimized Navigation Scheduling } \\
\hline & Sequence & $\begin{array}{l}\text { Departure } \\
\text { Time } \\
\text { (hh:mm:ss) }\end{array}$ & $\begin{array}{l}\text { Arrival Time } \\
\text { at the Pier } \\
\text { (hh:mm:ss) }\end{array}$ & $\begin{array}{l}\text { Waiting } \\
\text { Time } \\
\text { (Hour) }\end{array}$ & Sequence & $\begin{array}{l}\text { Departure } \\
\text { Time } \\
\text { (hh:mm:ss) }\end{array}$ & $\begin{array}{l}\text { Arrival Time } \\
\text { at the Pier } \\
\text { (hh:mm:ss) }\end{array}$ & $\begin{array}{l}\text { Waiting } \\
\text { Time } \\
\text { (Hour) }\end{array}$ \\
\hline 31 & 32 & $20: 36: 00$ & 21:41:00 & 3.4 & 31 & 19:19:00 & 20:51:00 & 2.1 \\
\hline 32 & 36 & 22:15:00 & $23: 20: 00$ & 4.9 & 32 & 19:24:00 & 21:14:00 & 2.0 \\
\hline 33 & 34 & $21: 35: 00$ & 22:40:00 & 3.3 & 33 & $20: 16: 00$ & 21:47:00 & 2.0 \\
\hline 36 & 31 & 20:04:00 & 21:09:00 & 0.1 & 36 & 22:16:00 & 23:53:00 & 2.3 \\
\hline 37 & 33 & 21:24:00 & 22:29:00 & 0.3 & 37 & 23:28:00 & 01:02:00 & 2.3 \\
\hline 38 & 40 & 01:23:00 & 02:28:00 & 3.6 & 38 & $00: 14: 00$ & 01:46:00 & 2.4 \\
\hline 39 & 37 & $22: 21: 00$ & 23:53:00 & 0.4 & 39 & 00:24:00 & 01:59:00 & 2.5 \\
\hline 40 & 39 & 00:59:00 & 02:04:00 & 2.9 & 40 & 01:16:00 & 02:52:00 & 3.2 \\
\hline
\end{tabular}

Table 3. Comparison of the vessel groups and the starting time of the lockage process in both original navigation scheduling and optimized navigation scheduling.

\begin{tabular}{ccccc}
\hline \multirow{2}{*}{ Group } & \multicolumn{2}{c}{ Original Navigation Scheduling } & \multicolumn{2}{c}{ Optimized Navigation Scheduling } \\
\cline { 2 - 5 } & Vessel Number & $\begin{array}{c}\text { Starting Time of the } \\
\text { Lockage Process }\end{array}$ & Vessel Number & $\begin{array}{c}\text { Starting Time of the } \\
\text { Lockage Process }\end{array}$ \\
\hline 1 & $1,2,4,6,7,9$ & $07: 12: 00$ & $1,2,3,4,5$ & $04: 25: 00$ \\
2 & $5,3,13,14$ & $09: 23: 00$ & $6,7,8,9,10$ & $07: 59: 00$ \\
3 & $15,8,16,10,17$ & $11: 46: 00$ & $11,12,13,14$ & $10: 10: 00$ \\
4 & $11,19,12,23$ & $14: 10: 00$ & $15,16,17,18,19$ & $13: 48: 00$ \\
5 & $25,18,28,20,22$ & $17: 52: 00$ & $20,21,22,23$ & $15: 48: 00$ \\
6 & $21,24,26,27$ & $19: 46: 00$ & $24,25,26,27,28$ & $18: 35: 00$ \\
7 & $29,30,36,31$ & $21: 41: 00$ & $29,30,31,32$ & $21: 14: 00$ \\
8 & $37,33,34,32$ & $23: 20: 00$ & $33,34,35,36$ & $23: 53: 00$ \\
9 & $39,35,40,38$ & $02: 28: 00$ & $37,38,39,40$ & $02: 52: 00$ \\
\hline
\end{tabular}

The comparison of the carbon emissions between original navigation scheduling and optimized navigation scheduling is given in Figure 5. As shown, the carbon emissions are dramatically reduced for all vessels in the optimized navigation scheduling. In the operational stage of the ship lock, the carbon emissions cannot be reduced because of the standard procedures required, and the reduction on carbon emissions is mainly from the change of waiting time through the optimized scheduling in Step 1 and speed adjustment in Step 2. Figure 6 shows the comparison of carbon emissions between the original navigation scheduling and the optimized navigation scheduling in different stages. As can be seen, the reduction on the overall carbon emissions is predominantly contributed by the speed adjustment in Step 2. The total emissions from the 40 vessels can be reduced by $58.8 \%$.

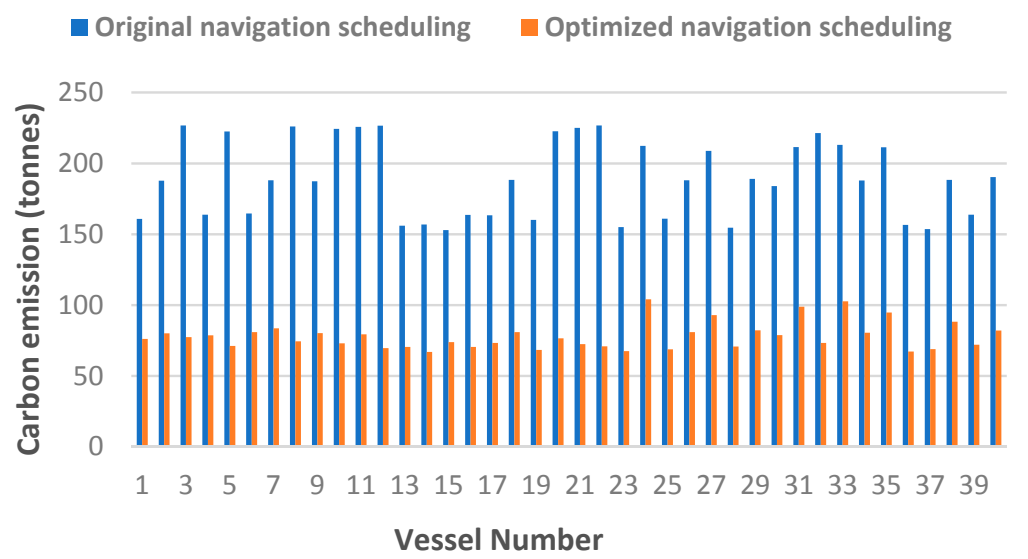

Figure 5. Comparison of the carbon emissions between original navigation scheduling and optimized navigation scheduling. 


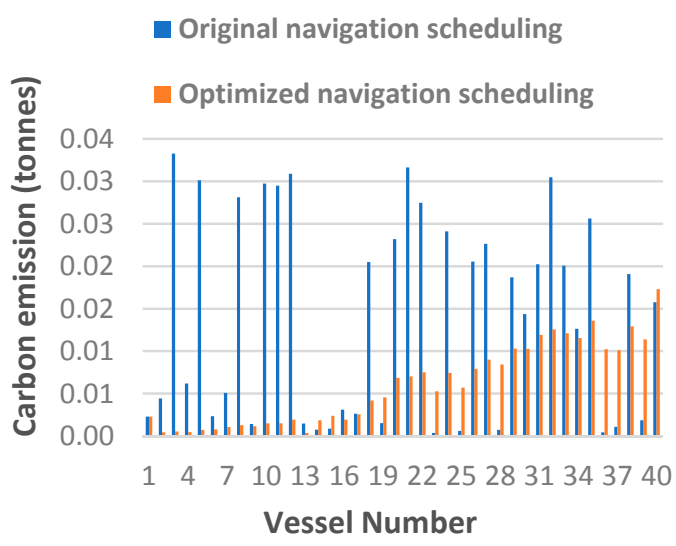

(a)

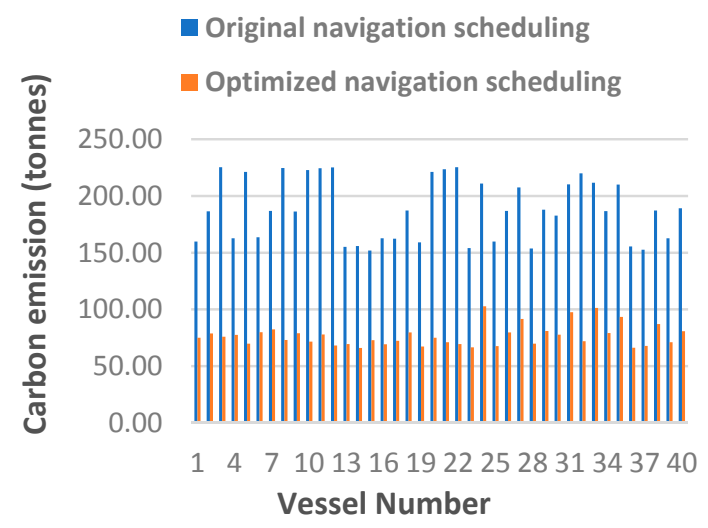

(b)

Figure 6. Comparison of carbon emission between the original navigation scheduling and optimized navigation scheduling in: (a) Step 1; (b) Step 2.

\subsection{Speed Adjustment}

In the numerical experiment, the vessel speed in the current navigation scheduling is $10 \mathrm{~km} / \mathrm{h}$. In the optimized navigation scheduling, each vessel is assigned to a given speed. On average, the speed is reduced by $3-4 \mathrm{~km} / \mathrm{h}$ in the optimal solution. This has led to a significant reduction on the carbon emissions from the vessels, especially from the high-weight ones, in passing through the Three Gorges Dam. Figure 7 presents the correlation between the total weight and speed of each vessel in the optimized navigation scheduling, and due to the tremendous difference in the measure of them, the vessel weights are first normalized by dividing by 1000 .

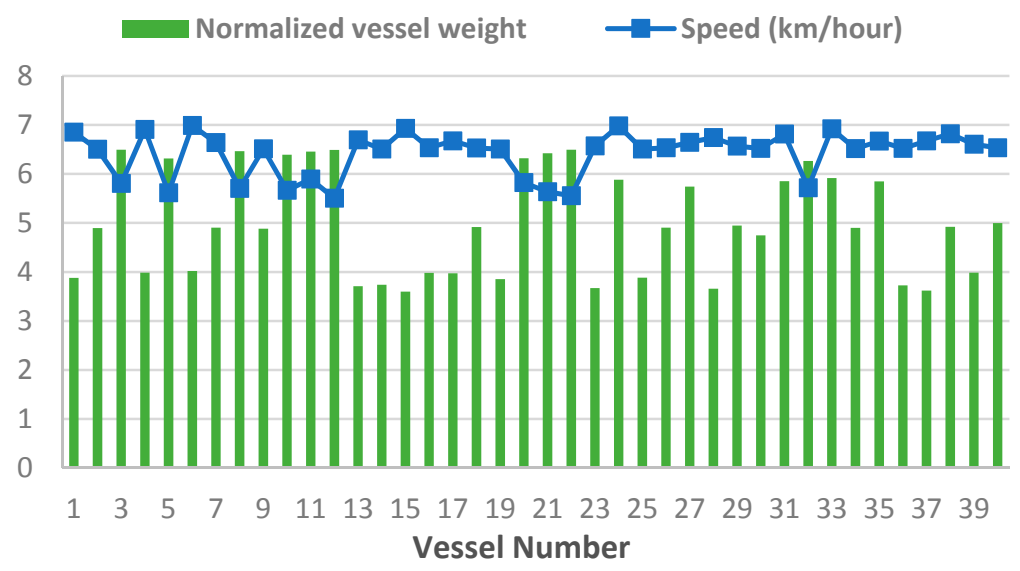

Figure 7. The correlation between the speed and normalized weight of each vessel in the optimized navigation scheduling.

As shown in the figure, the speed assigned to a vessel is inversely proportional to its weight. A high-weight vessel gets a lower speed (e.g., vessels 3, 8, 22, and 32) and vice versa. On the one hand, the lower speed of high-weight vessels can greatly reduce the fuel consumption and carbon emissions in step 2. However, on the other hand, this may lead to an inefficiency or slippage in the lockage scheduling. Thus, in the optimized navigation scheduling, higher speed is assigned to low-weight vessels in order to offset this impact and guarantee the efficiency of the lockage process. With the models developed in most of the previous research works, the primary objective is only to determine the lowest vessel speed that can minimize the fuel consumption and carbon emissions. In our research, we aim at, through the speed adjustment in step 2, reducing the fuel consumption and 
carbon emissions, while at the same time, maintaining the efficiency of the navigation scheduling at the Three Gorges Dam.

\subsection{The Correlation between Vessel Weight and Carbon Emission}

It is of interest to investigate the correlation between the vessel weight and the Reduction on Carbon Emissions by Speed Adjustment (RCESA) in step 2. RCESA is calculated using the reduction of carbon emissions in step 2 dividing by the reduction on speed, which means how much carbon emissions can be reduced by lowering down the vessel speed by $1 \mathrm{~km} / \mathrm{h}$. Table 4 presents the vessel sequence, weight and RCESA in the optimized navigation scheduling. As shown in the table, the high-weight vessels have larger RCESA in comparison with that of the low-weight ones, which means the reduction on the speed of high-weight vessels is more effective in decreasing the carbon emissions in step 2.

Table 4. The vessel sequence, weight and RCESA (reduction on carbon emissions in step 2/reduction on vessel speed) in the optimized navigation scheduling.

\begin{tabular}{|c|c|c|}
\hline Number & Vessel Weight (Tonnes) & RCESA \\
\hline 1 & 3878 & 26.9 \\
\hline 2 & 4894 & 30.8 \\
\hline 3 & 6496 & 35.6 \\
\hline 4 & 3985 & 27.5 \\
\hline 5 & 6317 & 34.5 \\
\hline 6 & 4019 & 27.8 \\
\hline 7 & 4906 & 31.1 \\
\hline 8 & 6465 & 35.3 \\
\hline 9 & 4881 & 30.7 \\
\hline 10 & 6392 & 34.9 \\
\hline 11 & 6457 & 35.7 \\
\hline 12 & 6489 & 34.9 \\
\hline 13 & 3709 & 25.9 \\
\hline 14 & 3739 & 25.7 \\
\hline 15 & 3599 & 25.7 \\
\hline 16 & 3983 & 26.9 \\
\hline 17 & 3972 & 27.1 \\
\hline 18 & 4917 & 30.9 \\
\hline 19 & 3853 & 26.3 \\
\hline 20 & 6322 & 35.0 \\
\hline 21 & 6421 & 35.0 \\
\hline 22 & 6496 & 35.0 \\
\hline 23 & 3672 & 25.5 \\
\hline 24 & 5884 & 35.8 \\
\hline 25 & 3883 & 26.4 \\
\hline 26 & 4904 & 30.9 \\
\hline 27 & 5740 & 34.5 \\
\hline 28 & 3658 & 25.7 \\
\hline 29 & 4948 & 31.1 \\
\hline 30 & 4746 & 30.2 \\
\hline 31 & 5854 & 35.3 \\
\hline 32 & 6265 & 34.6 \\
\hline 33 & 5918 & 35.8 \\
\hline 34 & 4899 & 30.8 \\
\hline 35 & 5848 & 35.0 \\
\hline 36 & 3727 & 25.7 \\
\hline 37 & 3620 & 25.4 \\
\hline 38 & 4919 & 31.5 \\
\hline 39 & 3986 & 27.0 \\
\hline 40 & 4997 & 31.3 \\
\hline
\end{tabular}


Furthermore, the correlation between the vessel weight and carbon emissions in step 2 for both original navigation scheduling and optimized navigation scheduling is given in Figure 8 , and the vessel weight is normalized by dividing by 30 . As can be seen, the carbon emissions in step 2 is proportional to the vessel weight when a constant speed is assigned to all vessels in the original navigation scheduling, and the carbon emissions generated from the high-weight vessels are much higher compared with that from the low-weight ones. However, in the optimized navigation scheduling, the impact of vessel weight on carbon emissions is weakened due to the speed adjustment on different vessels. Moreover, it is noteworthy that the carbon emissions from different vessels are leveled in the optimized navigation scheduling.

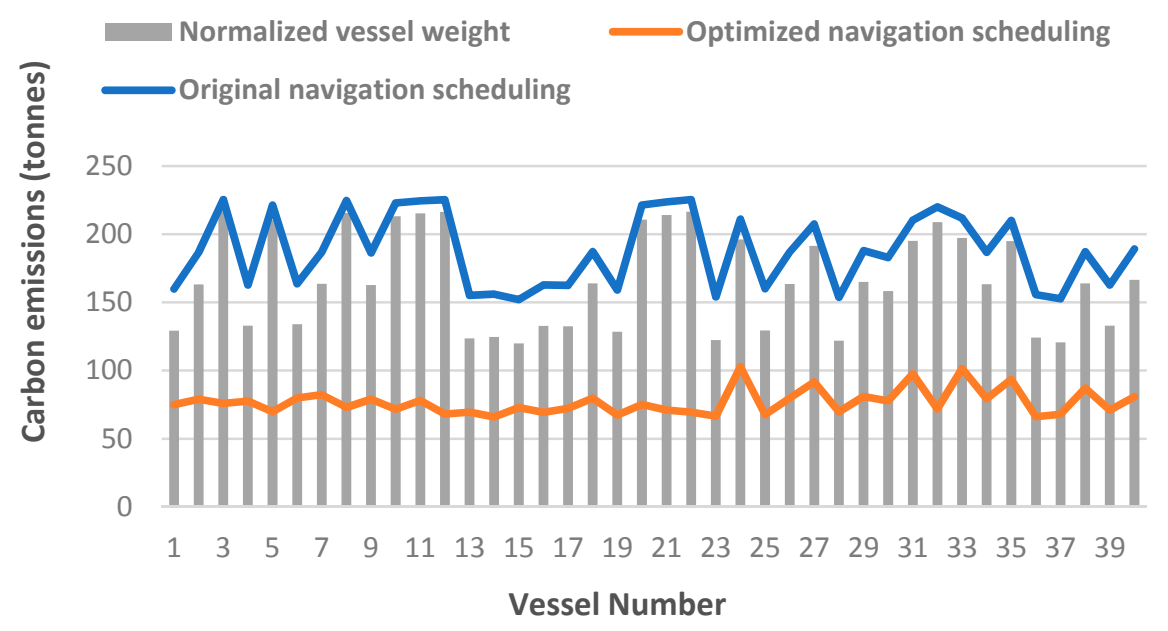

Figure 8. The correlation between vessel weight and carbon emissions in step 2.

\subsection{Reduction on Waiting Time and Improvement of the Fairness}

In the original navigation scheduling, low-weight vessels have priority in passing through the five-stage ship lock. Whenever those vessels arrive at the anchorage, they will be scheduled prior to the high-weight ones in the lockage process. Thus, with the optimized navigation scheduling, not only the vessel speed is adjusted, but also the scheduled departure time of the vessels is optimized in order to maintain the efficiency of the navigation scheduling at the Three Gorges Dam. Different from the current rule implemented in the navigation scheduling, the proposed model employs the principle of FCFS by imposing a maximum waiting time of each vessel arrived at the anchorage. In the optimized plan, the vessel sequence is predominantly determined by their arrival time, as shown in Figure 9.

$$
\diamond \text { Original navigation scheduling } \quad \text { Optimized navigation scheduling }
$$

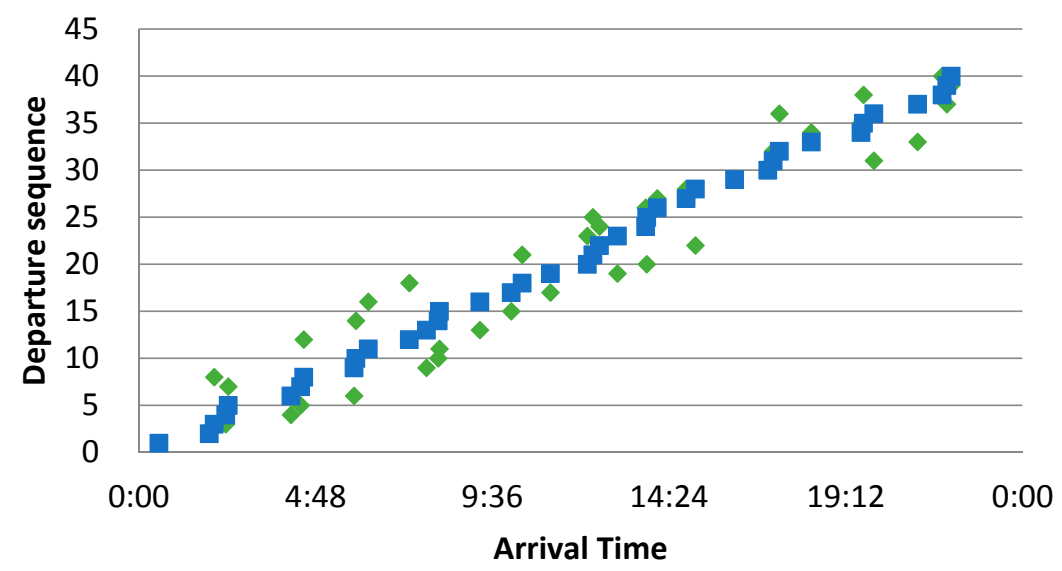

Figure 9. Comparison of vessel sequence in both original navigation scheduling and optimized navigation scheduling. 
For comparison purpose, the 40 vessels are divided into four groups based on their waiting time at the anchorage. The first group includes 10 vessels with the shortest waiting time, and the other groups are divided in the same way. Figure 10 presents the comparison of the total waiting time in each group between the original navigation scheduling and the optimized navigation scheduling. As can be seen, the total waiting time of the first group of vessels in the original navigation scheduling is slightly higher than that in the optimized navigation scheduling. However, the total waiting time for the vessels in the other groups is dramatically reduced in the optimized navigation scheduling, and the total waiting time of the 40 vessels is reduced by $52.7 \%$. The average waiting time is approximately $1 \mathrm{~h} 10 \mathrm{~min}$. The shortened waiting time of vessels reduces the carbon emissions as well as other environmental impact at the anchorage, and most importantly, it compensates the increase on the sailing time in step 2 due to the lower speed assigned and maintains the overall efficiency of the navigation scheduling.

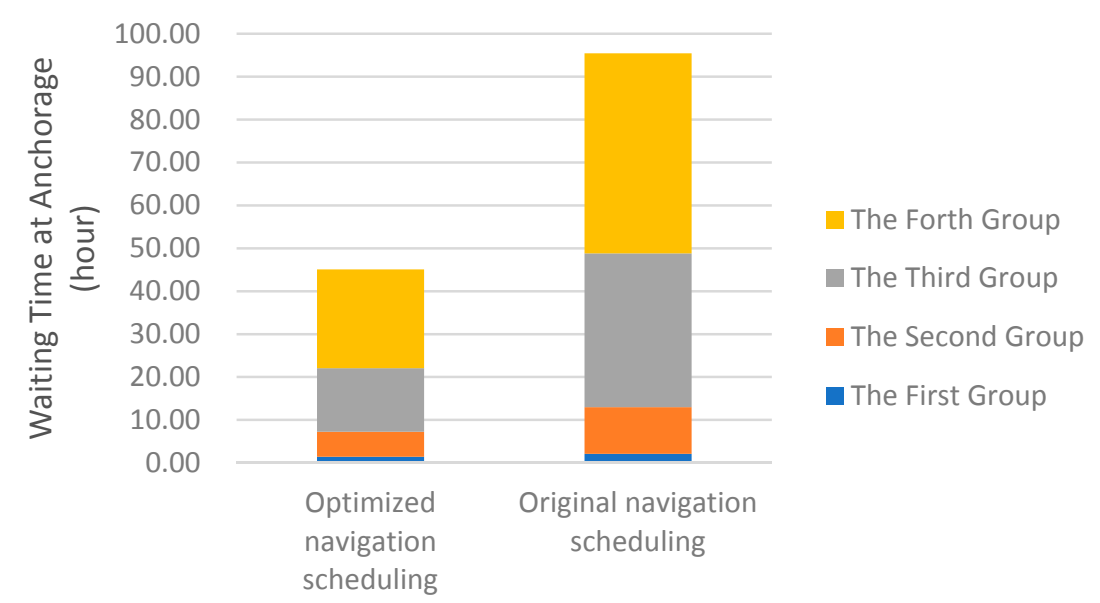

Figure 10. Comparison of the total waiting time of each group of vessels.

In addition, it is observed that the fairness of the navigation scheduling is improved in the optimal navigation scheduling. First, with the implementation of the rule of FCFS, instead of the vessel weight, the arrival time becomes the determinant for the vessel sequence in the optimized navigation scheduling so that the departure time of the high-weight vessels cannot be endlessly delayed on schedule due to the incoming low-weight vessels. Second, it is also noteworthy that the difference of the total waiting time among the four groups has been decreased in the optimized navigation scheduling. This reveals that, in comparison with the original navigation scheduling, the difference on the waiting time of different vessels is reduced and the fairness of the navigation scheduling is thus improved.

\subsection{Managerial Implications}

Through the numerical study of the model's behavior, some generic managerial implications into the green lock scheduling problem of the Three Gorges Dam can be summarized as follows.

- The carbon emissions from the vessels in passing through the Three Gorges Dam may be greatly reduced by optimizing the navigation scheduling. The reduction on carbon emissions of the overall lockage process is mainly contributed by the speed adjustment in the sailing from the anchorage to the gate of the ship lock.

- In the optimized planning, the overall efficiency of the navigation scheduling is not affected by the speed adjustment of the vessels due to the reduction on the average waiting time at the anchorage.

- Due to the proportionality between the cost and fuel consumption given in Section 4.4. The speed adjustment of vessels may also reduce the cost related to fuel consumptions, and the reduction on waiting time may minimize the risk of good damage at the anchorage. 
- The fairness of the navigation scheduling may also be improved through the implementation of the rule of FCFS and the reduction on the difference between the waiting time of different vessels.

\section{Conclusions}

In recent years, due to the increased waterway transportation on Yangtze River, the associated environmental problems have become a focus for both the Chinese government and the public. The Three Gorges Dam is the largest hydropower project on Yangtze River with a water-level difference at $175 \mathrm{~m}$ on both sides, and two five-stage ship locks are used for vessels over 3000 tones to pass through the dam. Because of the large amount of vessels in passing through the dam on both directions, the carbon emissions as well as other environmental impacts have become a great challenge. Therefore, an effective and efficient navigation scheduling is of paramount importance. However, the navigation scheduling at the Three Gorges Dam is a complex decision-making problem in which the vessel scheduling, speed, and lock capacity have to be simultaneously taken into account.

In this paper, we propose a new mathematical model for the green ship lock scheduling problem at the Three Gorges Dam. The model aims, by optimizing the navigation scheduling, at minimizing the overall environmental impact from the vessels in passing through the dam. The environmental impact is measured and formulated by carbon emissions. In addition, the economic performance is also taken into account in the model development. The proposed model is a mixed integer non-linear program and a NP-hard problem, so a G-PSO algorithm is developed in order to improve the computational efficiency. The mathematical model and G-PSO algorithm are validated through the numerical experiments. The result shows, through the optimization of the navigation scheduling, the overall carbon emissions from all vessels in passing through the dam can be significantly reduced without a compromise on the efficiency. Meanwhile, the fairness in the navigation scheduling may also be improved through the implementation of the FCFS rule.

Nevertheless, the current research has several limitations and further works may be done by addressing the following challenges:

1. The average area utilization rate (AUR) and lockage times of lock chamber problem in step 3 has not explicitly formulated in the current model. Besides, the cooperation between the ship lift and the ship lock is not taken into account. Thus, for further improvement, the modeling efforts may be done in order to improve the formulation in Step 3.

2. Even if the delay penalty is formulated in this paper, it has not been thoroughly tested in the experiments due to the lack of relevant information. Thus, future research may be conducted in order to test different economic means (e.g., different levels of delay penalty) for ensuring the efficiency of the navigation scheduling.

3. In addition, the navigation scheduling may be disrupted by unexpected events, i.e., accidents happened in the lockage process, equipment malfunction, etc., so the development of a decision-support tool for reactive strategy is of interest.

Author Contributions: All authors contribute substantially in this research work. X.Z. and Q.L. proposed the research idea and performed literature review, mathematical modelling, algorithm design, data acquisition, numerical experiment, and writing of the original draft. H.Y. improved the research design and mathematical modelling, and revised the paper. The final version has been approved by all authors.

Funding: This research is funded by the National Natural Science Foundation of China (Grand no. 71401090, Grand no. 71874101) and the Research Council of Norway under Transport 2025 Programme (Grand no. 283084). The Article Processing Charge is financially supported by the Open Access Fund at UiT The Arctic University of Norway.

Acknowledgments: The authors would like to express their gratitude to the anonymous reviewers whose valuable comments have helped to drastically improve the quality and presentation of this research.

Conflicts of Interest: The authors declare no conflict of interest. 


\section{References}

1. Cleveland, C.J.; Morris, C. Volume II: Chronologies, Top Ten Lists, and Word Clouds. In Handbook of Energy; Elsevier: Boston, MA, USA, 2014; p. 4.

2. Lindstad, H.; Asbjørnslett, B.E.; Strømman, A.H. The importance of economies of scale for reductions in greenhouse gas emissions from shipping. Energy Policy 2012, 46, 386-398. [CrossRef]

3. Wang, S.; Meng, Q.; Liu, Z. Containership scheduling with transit-time-sensitive container shipment demand. Transp. Res. Part B Methodol. 2013, 54, 68-83. [CrossRef]

4. Agarwal, R.; Ergun, Ö. Ship Scheduling and Network Design for Cargo Routing in Liner Shipping. Transp. Sci. 2008, 42, 175-196. [CrossRef]

5. Christiansen, M.; Fagerholt, K. Robust ship scheduling with multiple time windows. Nav. Res. Logist. 2010, 49, 611-625. [CrossRef]

6. Dulebenets, M. A comprehensive multi-objective optimization model for the vessel scheduling problem in liner shipping. Int. J. Prod. Econ. 2017, 196, 293-318. [CrossRef]

7. Venturini, G.; Iris, Ç.; Kontovas, C.A.; Larsen, A. The multi-port berth allocation problem with speed optimization and emission considerations. Transp. Res. Part D Transp. Environ. 2017, 54, 142-159. [CrossRef]

8. Umang, N.; Bierlaire, M.; Erera, A.L. Real-time management of berth allocation with stochastic arrival and handling times. J. Sched. 2017, 20, 67-83. [CrossRef]

9. Dulebenets, M.A.; Kavoosi, M.; Abioye, O.; Pasha, J. A Self-Adaptive Evolutionary Algorithm for the Berth Scheduling Problem: Towards Efficient Parameter Control. Algorithms 2018, 11, 100. [CrossRef]

10. Lalla-Ruiz, E.; Shi, X.; Voß, S. The waterway ship scheduling problem. Transp. Res. Part D Transp. Environ. 2016, 60, 191-209. [CrossRef]

11. Elwany, M.H.; Ali, I.; Abouelseoud, Y. A heuristics-based solution to the continuous berth allocation and crane assignment problem. Alex. Eng. J. 2013, 52, 671-677. [CrossRef]

12. Li, M.W.; Hong, W.C.; Geng, J.; Wang, J. Berth and quay crane coordinated scheduling using multi-objective chaos cloud particle swarm optimization algorithm. Neural Comput. Appl. 2017, 28, 3163-3182. [CrossRef]

13. Zhen, L.; Liang, Z.; Zhuge, D.; Lee, L.H.; Chew, E.P. Daily berth planning in a tidal port with channel flow control. Transp. Res. Part B Methodol. 2017, 106, 193-217. [CrossRef]

14. Xiang, X.; Liu, C.; Miao, L. Reactive strategy for discrete berth allocation and quay crane assignment problems under uncertainty. Comput. Ind. Eng. 2018, 126, 196-216. [CrossRef]

15. Chuang, T.N.; Lin, C.T.; Kung, J.Y.; Lin, M.D. Planning the route of container ships: A fuzzy genetic approach. Expert Syst. Appl. 2010, 37, 2948-2956. [CrossRef]

16. Lindstad, H.; Asbjørnslett, B.E.; Strømman, A.H. Reductions in greenhouse gas emissions and cost by shipping at lower speeds. Energy Policy 2011, 39, 3456-3464. [CrossRef]

17. Psaraftis, H.N.; Kontovas, C.A. Speed models for energy-efficient maritime transportation: A taxonomy and survey. Transp. Res. Part C Emerg. Technol. 2013, 26, 331-351. [CrossRef]

18. Dulebenets, M.A.; Golias, M.M.; Mishra, S. The green vessel schedule design problem: Consideration of emissions constraints. Energy Syst. 2015, 8, 761-783. [CrossRef]

19. Du, Y.; Chen, Q.; Quan, X.; Long, L.; Fung, R.Y.K. Berth allocation considering fuel consumption and vessel emissions. Transp. Res. Part E Logist. Transp. Rev. 2011, 47, 1021-1037. [CrossRef]

20. Dulebenets, M. Green Vessel Scheduling in Liner Shipping: Modeling Carbon Dioxide Emission Costs in Sea and at Ports of Call. Int. J. Transp. Sci. Technol. 2017, 7, 26-44. [CrossRef]

21. Wang, S.; Meng, Q.; Liu, Z. A note on "Berth allocation considering fuel consumption and vessel emissions". Transp. Res. Part E Logist. Transp. Rev. 2013, 49, 48-54. [CrossRef]

22. Bialystocki, N.; Konovessis, D. On the estimation of ship's fuel consumption and speed curve: A statistical approach. J. Ocean Eng. Sci. 2016, 1, 157-166. [CrossRef]

23. Kontovas, C.A. The Green Ship Routing and Scheduling Problem (GSRSP): A conceptual approach. Transp. Res. Part D Transp. Environ. 2014, 31, 61-69. [CrossRef]

24. Passchyn, W.; Briskorn, D.; Spieksma, F.C.R. Mathematical programming models for lock scheduling with an emission objective. Eur. J. Oper. Res. 2016, 248, 802-814. [CrossRef]

25. Ting, C.J.; Schonfeld, P. Effects of Speed Control on Tow Travel Costs. J. Waterw. Port Coast. Ocean Eng. 1999, 125, 203-206. [CrossRef] 
26. Ting, C.J.; Schonfeld, P. Control Alternatives at a Waterway Lock. J. Waterw. Port Coast. Ocean Eng. 2001, 127, 89-96. [CrossRef]

27. Polyakovskiy, S.; M'Hallah, R. A Hybrid Feasibility Constraints-Guided Search to the Two-Dimensional Bin Packing Problem with Due Dates. Eur. J. Oper. Res. 2018, 266, 819-839. [CrossRef]

28. Verstichel, J.; Causmaecker, P.D.; Spieksma, F.; Berghe, G.V. The generalized lock scheduling problem: An exact approach. Transp. Res. Part E Logist. Transp. Rev. 2014, 65, 16-34. [CrossRef]

29. Ji, B.; Yuan, X.; Yuan, Y. Orthogonal Design-Based NSGA-III for the Optimal Lockage Co-Scheduling Problem. IEEE Trans. Intell. Transp. Syst. 2017, 18, 2085-2095. [CrossRef]

30. Yuan, X.; Ji, B.; Yuan, Y.; Wu, X.; Zhang, X. Co-scheduling of lock and water-land transshipment for ships passing the dam. Appl. Soft Comput. 2016, 45, 150-162. [CrossRef]

31. Latorre, R. Reducing fishing vessel fuel consumption and NO X emissions. Ocean Eng. 2001, 28, 723-733. [CrossRef]

32. Cullinane, K.; Bergqvist, R. Environment, Emission control areas and their impact on maritime transport. Transp. Res. Part D Transp. Environ. 2014, 28, 1-5. [CrossRef]

33. Zhen, L.; Shen, T.; Wang, S.; Yu, S. Models on ship scheduling in transshipment hubs with considering bunker cost. Int. J. Prod. Econ. 2016, 173, 111-121. [CrossRef]

34. Qi, X.; Song, D.P. Minimizing fuel emissions by optimizing vessel schedules in liner shipping with uncertain port times. Transp. Res. Part E Logist. Transp. Rev. 2012, 48, 863-880. [CrossRef]

35. Corbett, J.J.; Wang, H.; Winebrake, J.J. The effectiveness and costs of speed reductions on emissions from international shipping. Transp. Res. Part D Transp. Environ. 2009, 14, 593-598. [CrossRef]

36. IMO (International Maritime Organization). Second IMO GHG Study 2009. 2009. Available online: http://www.imo.org/en/OurWork/Environment/PollutionPrevention/AirPollution/Documents/ SecondIMOGHGStudy2009.pdf (accessed on 7 May 2019).

37. Zhen, L.; Wang, S.; Wang, K. Terminal allocation problem in a transshipment hub considering bunker consumption: TAP in a Transshipment Hub. Nav. Res. Logist. 2016, 63, 529-548. [CrossRef]

38. Fagerholt, K.; Christiansen, M. A travelling salesman problem with allocation, time window and precedence constraints-An application to ship scheduling. Int. Trans. Oper. Res. 2000, 7, 231-244. [CrossRef]

39. Reinhardt, L.B.; Plum, C.E.M.; Pisinger, D.; Sigurd, M.M.; Vial, G.T.P. The liner shipping berth scheduling problem with transit times. Transp. Res. Part E Logist. Transp. Rev. 2016, 86, 116-128. [CrossRef]

40. Zhang, X.; Lin, J.; Guo, Z.; Liu, T. Vessel transportation scheduling optimization based on channel-berth coordination. Ocean Eng. 2016, 112, 145-152. [CrossRef]

41. Liu, B.; Wang, L.; Jin, Y.; Huang, D. An Effective PSO-Based Memetic Algorithm for TSP. In Proceedings of the Intelligent Computing in Signal Processing and Pattern Recognition: International Conference on Intelligent Computing, ICIC 2006, Kunming, China, 16-19 August 2006; Huang, D.S., Li, K., Irwin, G.W., Eds.; Springer: Berlin/Heidelberg, Germany, 2006; pp. 1151-1156.

42. Mokarram, V.; Banan, M.R. A new PSO-based algorithm for multi-objective optimization with continuous and discrete design variables. Struct. Multidiscip. Optim. 2018, 57, 509-533. [CrossRef]

(C) 2019 by the authors. Licensee MDPI, Basel, Switzerland. This article is an open access article distributed under the terms and conditions of the Creative Commons Attribution (CC BY) license (http://creativecommons.org/licenses/by/4.0/). 